\title{
THE EFFECT OF A SINGLE DOSE OF CADMIUM CHLORIDE ON THE PHOSPHOLIPID FATTY ACIDS OF THE RAT TESTIS
}

\author{
D. J. W. LEE* AND M. McC. BARNES \\ Department of Biochemistry, University of Liverpool
}

(Received 23rd September 1970, revised 19th January 1971)

\begin{abstract}
Summary. Young adult male rats were given $0.12 \mathrm{mg} \mathrm{CdCl}_{2} / 100 \mathrm{~g}$ b.wt by intraperitoneal injection and the resulting testicular degeneration was studied over a period of 3 months. The testicular degeneration due to a single injection of $\mathrm{CdCl}_{2}$ has been shown to have a profound effect on the weights of the testes, testicular total lipid and phospholipid and on the proportions of testicular phospholipid fatty acids. Increases in the percentage of 18:0,18:2 $\omega 6,20: 3 \omega 6,20: 4 \omega 6$ and

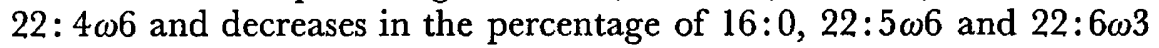
were observed. The association of $22: 5 \omega 6$ with spermatogenesis has been confirmed and it is suggested that nearly all the $22: 5 \omega 6$ in the intact mature testis is located in the germinal epithelium, spermatids and spermatozoa.
\end{abstract}

\section{INTRODUCTION}

A single dose of cadmium chloride $(0.68 \mathrm{mg} / 100 \mathrm{~g} \mathrm{b.wt})$ causes an irreversible degeneration of the germinal epithelium of rat testes (Pařízek, 1956, 1957). The onset of degeneration is rapid and identical to that seen when the spermatic artery has been ligated. Mason, Brown, Young \& Nesbit (1963) found that as the dose of cadmium chloride was reduced, the onset of testicular degeneration was delayed, and the degeneration proceeded at a slower rate. When a smaller dose $(0.10$ to $0.12 \mathrm{mg} \mathrm{CdCl} / 100 \mathrm{~g} \mathrm{~b} . w \mathrm{t})$ was administered, there was no rapid necrosis of the germinal epithelium; instead, degenerative changes occurred in the testes with the formation of giant cells. These changes were very similar to those seen in vitamin E deficiency. Mason et al. (1963) called this degeneration 'non-necrotic' degeneration. Vitamin E, given before, after or simultaneously with cadmium chloride did not exert a protective effect and the testes fromrats deficient in vitamin $\mathbf{E}$ were not more sensitive to cadmium injury (Mason, Brown, Young \& Nesbit, 1964).

The experiment described here, shows that marked changes occur in the phospholipid fatty acids from testes injured by cadmium. A preliminary report of these findings has been given previously (Lee \& Barnes, 1967).

\section{EXPERIMENTAL}

Young adult, male, hooded rats (Animal Suppliers Ltd, London) weighing

* Present address: Poultry Research Centre, King's Buildings, West Mains Road, Edinburgh 9. 
about $200 \mathrm{~g}$ were used. Cadmium chloride $\left(\mathrm{CdCl}_{2} \cdot 2 \frac{1}{2} \mathrm{H}_{2} \mathrm{O}, \mathrm{BDH}\right.$ Chemicals Ltd, Poole) was dissolved in $0.9 \%(\mathrm{w} / \mathrm{v}) \mathrm{NaCl}$ to give a solution containing $0.12 \mathrm{mg} \mathrm{CdCl} / 2 / 0.1 \mathrm{ml}$. The solution was sterilized by autoclaving at $13 \mathrm{lb} / \mathrm{in}^{2}$ for $15 \mathrm{~min}$; the $\mathrm{pH}$ after autoclaving was 6.5 . Each rat was given $0 \cdot 1 \mathrm{ml} / 100 \mathrm{~g}$ b.wt by intraperitoneal injection.

Three rats were killed immediately after being injected and were used as the Day 0 group (controls). Groups of three rats were killed at different times ( 1 to 84 days) after injection. The testes from each rat were removed and weighed. One testis was kept for histological examination in order to compare the degree of degeneration with the fatty acid pattern observed in the other testis from the same rat. Methyl esters of the phospholipid fatty acids were prepared from the second testis using the methods described previously (Lee \& Barnes, 1969).

Total lipid was extracted by the method of Albrink (1959-60) and phospholipid separated by silicic acid-celite column chromatography, based on the method of Borgström (1952). The phospholipid was transmethylated by heating under reflux with boron trifluoride-methanol complex (about $14 \% \mathrm{BF}_{3}, \mathrm{BDH}$ Chemicals Ltd) for $20 \mathrm{~min}$. The fatty acid methyl esters were separated by gas liquid chromatography using an F and M 810 Research Chromatograph fitted with a flame ionization detector. The column packing was $10 \%$ polyethylene glycol adipate, argon was used as the carrier gas and the column temperature was $192^{\circ} \mathrm{C}$.

\section{RESULTS}

The analytical results that were obtained after injection of $0.12 \mathrm{mg} \mathrm{CdCl}_{2} / 100 \mathrm{~g}$ b.wt are summarized in Table 1.

Testis weights tended to increase soon after injection. Thus, on Day 2, two rats had testes weighing 2.92 and $2.98 \mathrm{~g}$ compared to an average of about $2.4 \mathrm{~g}$ in those rats killed on Day 0: these testes were firm and oedematous. Thereafter, weights decreased sharply although there were wide variations. For example, on Day 10, two rats had testes weighing about $1.1 \mathrm{~g}$ while on Day 21 , one rat had testes of normal (Day 0) weight.

Total lipids decreased rapidly during the 1st day, remained at an approximately constant level for several days, and then decreased slowly. Levels of phospholipid showed little change during the first 4 days but declined considerably during Days 5 to 14 . Both total lipids and phospholipids appeared to increase slightly between Day 28 and Day 84 . As the testis weights and the levels of phospholipid fatty acid declined, the percentage distribution of most of the individual fatty acids changed in a characteristic manner. From comparisons between Day 0 and Day 84, the fatty acids can be grouped as follows, using the nomenclature to denote the position of the first double band from the $\omega$, or terminal methyl, end of the fatty acid:

(1) those fatty acids which exhibited a significant increase in percentage, 18:0 $(P<0.010), 18: 2 \omega 6(P<0.001), 20: 3 \omega 6(P<0.050), 20: 4 \omega 6(P<0.005)$ and $22: 4 \omega 6(P<0.005)$. 


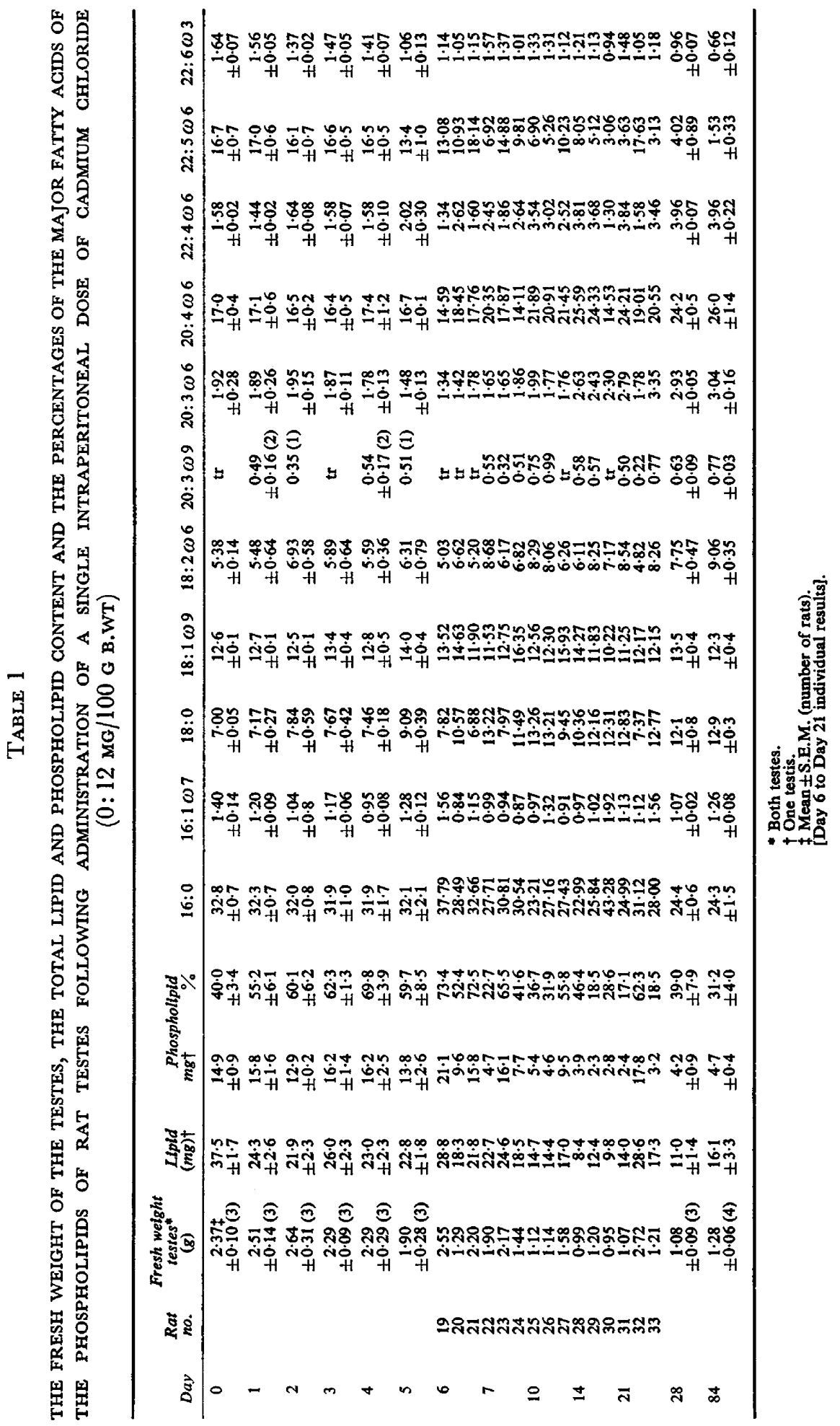


(2) those fatty acids which exhibited only slight variations in percentage, $16: 1 \omega 7,18: 1 \omega 9$ and $20: 3 \omega 9$.

(3) those fatty acids which exhibited a significant decrease in percentage,

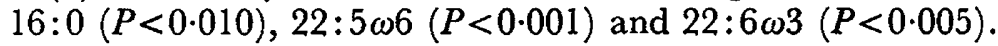

The most marked changes were in the fatty acids $16: 0,18: 0,20: 4 \omega 6$ and $22: 5 \omega 6$.

Some rats were apparently hypersensitive to cadmium: thus, at 6 to 7 days, rats 20 and 22 showed testis weights and fatty acid distributions that were comparable to analytical figures obtained at 10 to 14 days. However, other rats $(21,23,27$ and especially 32) showed varying degrees of resistance to cadmium. Among these animals, the smaller the decline in testis weight the smaller were the changes in the distribution pattern of fatty acids. This is especially marked in terms of $\mathrm{mg}$ phospholipid and of percentage of 22:5 $\omega 6$. Percentage values for individual fatty acids showed little change during Days 0 to 5 except for 18:2 $\omega 6$ which increased transiently at Days 2 to 3 . The major changes in percentage distribution occurred between Day 6 and Day 14 .

In the histological sections of the testes, both 'ischaemic' and 'non-necrotic' degeneration as described by Mason et al. (1963) were observed. The severity of the testicular degeneration, based on the loss of germinal epithelium, corresponded with the magnitude of the fatty acid changes.

\section{DISCUSSION}

The interpretation of fatty acid patterns in the testis is complicated by the presence of spermatids and spermatozoa which may account for more than $60 \%$ of the volume of the testis tissue (Roosen-Runge, 1956). Thus, lipids of the spermatids may dominate the lipid and fatty acid pattern of the whole organ. Any change which causes the germinal epithelium to degenerate, with consequent decrease in formation of spermatozoa, would be expected to produce changes in the fatty acid pattern. Davis, Bridges \& Coniglio (1966) reported that rat epididymal spermatozoa contained 26.3\%16:0,17.9\%20:4 and 16.4\% 22:5, levels similar to those of the total testis. These levels are approximately the same as those reported in Table 1 for the phospholipid fraction of testis. The major change following cadmium injury is the almost complete loss of 22:5 $\omega 6$. This acid is only present in appreciable amounts in testis tissue (e.g. see Lee \& Barnes, 1969), and would appear to be closely associated with spermatogenesis. Davis et al. (1966) found an increase in concentration of 22:5 $\omega 6$ in the phospholipid fraction of the testis of the developing rat which was associated with the appearance and maturation of the spermatids. The loss of $22: 5 \omega 6$ from the testis in conditions which cause sterility has been demonstrated by a number of workers, e.g. in vitamin E deficiency by Bieri \& Andrews (1964) and Lee \& Barnes (1969), in essential fatty acid deficiency by Walker (1968), who also demonstrated the close correlation between the rise in the level of $22: 5 \omega 6$ and the appearance of spermatozoa during recovery from the deficiency. But in none of these cases was the loss of 22:5 16 as complete as the loss observed here.

It seems likely that the change in the fatty acid pattern was a result of loss of 
germinal epithelium, spermatids and spermatozoa. The fatty acid changes at 84 days were greater than those at 28 days, even though there appeared to have been some slight recovery of the testes in terms of total lipid and phospholipid. In the light of observations by Pařizek (1956, 1957), it is interesting that cadmium injury can cause temporary destruction of the interstitial cells in addition to the irreversible massive destruction of the germinal epithelium. It is possible that a similar effect has occurred in this experiment and that some regeneration of the interstitial cells has taken place by the 84th day. It is suggested that the fatty acid pattern obtained at 84 days approximates to the fatty acid composition of the interstitial cells. The association of $22: 5 \omega 6$ with the germinal epithelium and spermatogenesis has been clearly demonstrated. Nearly all the 22:5 $\omega 6$ present in the normal testis would appear to be located in the germinal epithelium, spermatids and spermatozoa.

\section{AGKNOWLEDGMENTS}

We are grateful to the A.R.G. for a Research Studentship (D.J.W.L.). We are also grateful to the Department of Veterinary Pathology for the preparation of testicular sections.

\section{REFERENCES}

ALBRINK, M. J. (1959-60) The microtitration of total fatty acids of serum with notes on the estimation of triglycerides. F. Lipid Res. 1, 53.

BIERI, J. G. \& ANDREws, E. L. (1964) Fatty acids in rat testis as affected by vitamin E. Biochem. biophys. Res. Commun. 17, 115.

Borcström, B. (1952) Separation of phospholipids from neutral fat and fatty acids. Acta physiol. scand. 25, 101 .

Davis, J. T., Bridges, R. B. \& Coniglio, J. G. (1966) Changes in the lipid composition of the maturing rat testis. Biochem. 7. 98, 342.

LEE, D. J. W. \& BARNEs, M. MCC. (1967) The effect of cadmium injury on phospholipid fatty acids of rat testis compared with the effects of vitamin $\mathrm{E}$ deficiency. Biochem. F. 103, 30P.

LEE, D. J. W. \& BARNEs, M. MCC. (1969) The effect of vitamin E deficiency on the total fatty acids and the phospholipid fatty acids of rat tissues. Br. F. Nutr. 23, 289.

Mason, K. E., Brown, J. A., Youno, J. O. \& Nesbit, R. R. (1963) Cadmium-induced injury of the rat testis. Anat. Rec. 145, 257.

Mason, K. E., Brown, J. A., Young, J. O. \& NesBrt, R. R. (1964) Gadmium-induced injury of the rat testis. Anat. Rec. 149, 135.

Paḱízex, J. (1956) Effect of cadmium salts on testicular tissue. Nature, Lond. 177, 1036.

PaḱfzeK, J. (1957) The destructive effect of cadmium ion on testicular tissue and its prevention by zinc. F. Endocr. 15, 56.

Roosen-RUNGe, E. G. (1956) Quantitative investigations on human testicular biopsies. 1. Normal testis. Fert. Steril. 7, 251.

WALKER, B. L. (1968) Recovery of rat tissue lipids from essential fatty acid deficiency: brain, heart and testes. $\mathcal{F}$. Nutr. 94, 469. 